\title{
On the Mechanism of Thermal Adaptation in the Lactate Dehydrogenases
}

\author{
Supplemental \\ Huo-Lei Peng, Tsuyoshi Egawa, Eric Chang, Hua Deng, and Robert Callender \\ \$Department of Biochemistry, Albert Einstein College of Medicine, Bronx, NY 10461 \\ * Phone: 718-430-3024, Fax: 718-430-8565, E-mail: robert.callender@einstein.yu.edu
}

\section{ISOTOPE EDITED FTIR DIFFERENCE SPECTRA}

Figure 1S shows isotope edited FTIR spectra in the region of the $\mathrm{C}_{2}=\mathrm{O}$ stretch of oxamate (positive going peaks are ${ }^{13} \mathrm{C}_{2}=\mathrm{O}$ stretch, negative ones are ${ }^{12} \mathrm{C}_{2}=\mathrm{O}$ ) within the $\mathrm{LDH} \cdot \mathrm{NADH} \bullet$ oxamate complex for the extreme thermophile thermotoga Maritima (tmLDH), mesophile pig heart (phLDH), and Charmpsocephalus gunnari (cgLDH) lactate dehydrogenases, all spectra taken at room temperature. Oxamate has been labeled at the $\mathrm{C} 2$ position (the $\mathrm{C}_{2}=\mathrm{O}$ bond) with ${ }^{13} \mathrm{C}$. Any vibrational mode of the complex that is affected by ${ }^{13} \mathrm{C}$ labeling shifts in frequency so that a difference spectrum made up from subtracting $\mathrm{LDH} \cdot \mathrm{NADH} \cdot\left[{ }^{12} \mathrm{C}_{2}\right]$ oxamate $\mathrm{LDH} \cdot \mathrm{NADH} \cdot\left[{ }^{13} \mathrm{C}_{2}\right]$ oxamate yields a spectrum with only those modes affected by the label; all other, specifically protein, modes subtract out identically. Oxamate's $\mathrm{C}_{2}=\mathrm{O}$ stretch mode is easily identified and assigned since it undergoes a ca. $40 \mathrm{~cm}^{-1}$ frequency shift by ${ }^{13} \mathrm{C}$ labeling. For example, the two central $\mathrm{C}_{2}=\mathrm{O}$ stretch bands of the pig heart spectrum lie at 1606.4 and 
$1622.8 \mathrm{~cm}^{-1}$ for $\left[{ }^{13} \mathrm{C}_{2}\right]$ oxamate, and these are shifted to 1644.0 and $1656.6 \mathrm{~cm}^{-1}$ for $\left[{ }^{12} \mathrm{C}_{2}\right]$ oxamate. The pig heart difference spectrum is reproduced here from refs. ${ }^{1-2}$, where the subtraction procedures and assignments are thoroughly detailed.

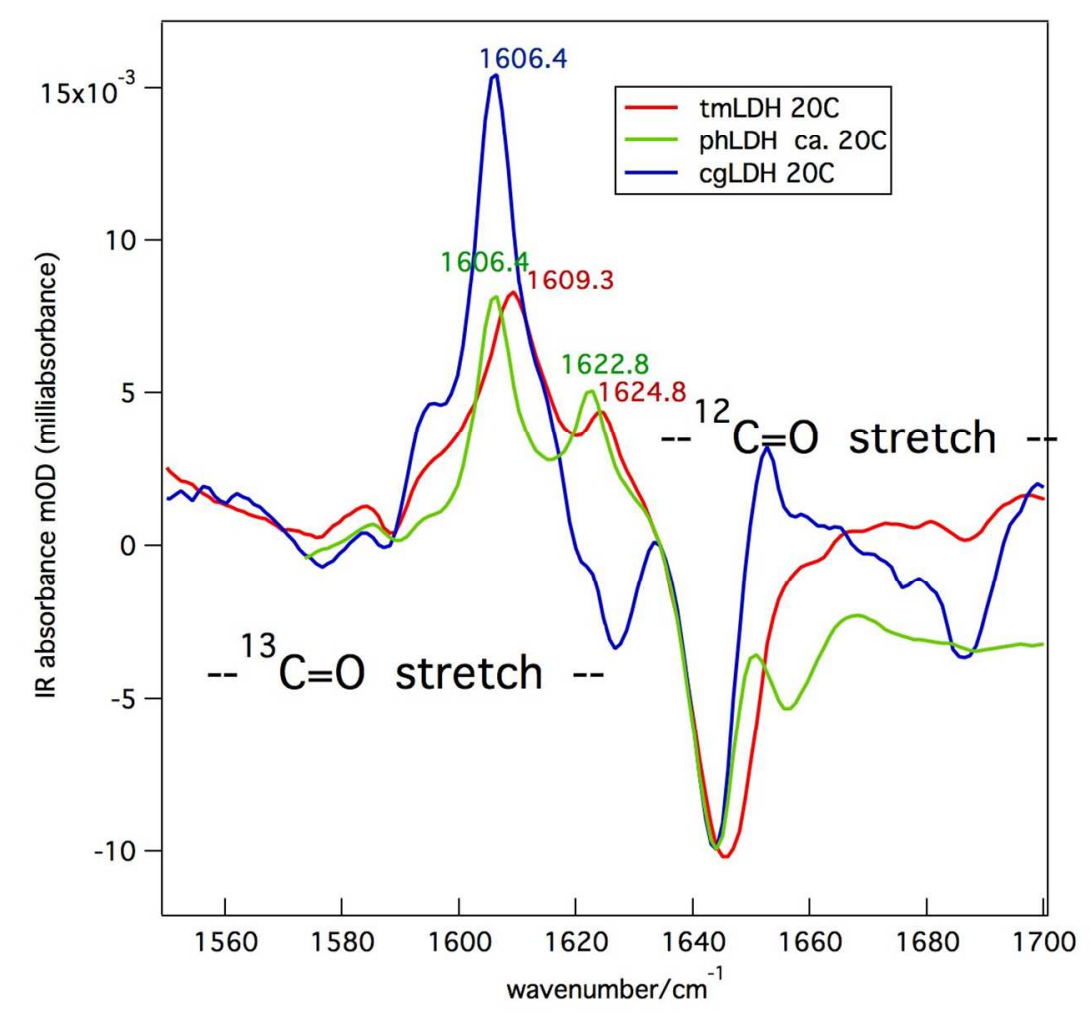

Figure 1S Isotope edited FTIR spectra in the region of the $\mathrm{C}_{2}=\mathrm{O}$ stretch of oxamate (positive going peaks are ${ }^{13} \mathrm{C}_{2}=\mathrm{O}$ stretch) within the $\mathrm{LDH} \bullet \mathrm{NADH} \bullet$ oxamate complex for the extreme thermophile thermotoga Maritima (tmLDH), mesophile pig heart (phLDH), and Charmpsocephalus gunnari (cgLDH) lactate dehydrogenases. Results taken at room temperature.

The multiple bands for each species means that the mimic is bound in multiple conformations. This behavior is very much like that found in studies of the actual Michaelis complex system, $\mathrm{LDH} \cdot \mathrm{NADH} \cdot$ pyruvate, where pyruvate is found to bind in multiple conformations with varying $\mathrm{C}_{2}=\mathrm{O}$ stretch frequencies. ${ }^{3}$ Many studies have shown that the conformations with more 
downshifted $\mathrm{C}_{2}=\mathrm{O}$ stretches have a greater propensity for carrying out on-enzyme chemistry. ${ }^{4-5}$ Hence, we have argued that the substate population which has a downshifted $\mathrm{C}_{2}=\mathrm{O}$ stretch, $1606.4 \mathrm{~cm}^{-1}$ in the $\mathrm{phLDH} \cdot \mathrm{NADH} \cdot\left[{ }^{13} \mathrm{C}_{2}\right]$ oxamate spectrum of Fig. $1 \mathrm{~S}$, represents a relatively active conformation while that at $1622.8 \mathrm{~cm}^{-1}$ is quite inactive. In addition, it has been shown $\mathrm{n}^{2,6-}$

${ }^{7}$ that the packing of NADH against oxamate within phLDH•NADH•oxamate brings about a much more reactive NADH conformation for the $1606.4 \mathrm{~cm}^{-1}$ species compared to that of 1622.8 $\mathrm{cm}^{-1}$. There is a minor intense band at $1595 \mathrm{~cm}^{-1}$ in the $\operatorname{cgLDH} \cdot \mathrm{NADH} \cdot\left[{ }^{13} \mathrm{C}_{2}\right]$ oxamate spectrum of Fig. 1S which appears to have corresponding negative intensity in the $\operatorname{cgLDH} \bullet \mathrm{NADH} \bullet\left[{ }^{12} \mathrm{C}_{2}\right]$ oxamate spectrum at $1627 \mathrm{~cm}^{-1}$, a $32 \mathrm{~cm}^{-1}$ shift. The intensity of this band is small, and we are unsure if it represents a real subpopulation of $\operatorname{cgLDH} \bullet \mathrm{NADH} \bullet$ oxamate. If so, it would represent a substate with a large propensity towards catalysis.

\section{TEMPERATURE DEPENDENCE OF IR BANDS OF BOUND OXAMATE.}

The temperature dependence of oxamate's $\mathrm{C}_{2}=\mathrm{O}$ stretch for the three LDH isozymes are shown in Figures 2(a-c). The main oxamate ${ }^{13} \mathrm{C}_{2}=\mathrm{O}$ stretch frequencies near $1605 \mathrm{~cm}^{-1}$ in these three LDH isozymes do not show significant change with temperature. However, this band intensity decreases with temperature increase. This is more obvious in phLDH and tmLDH in which the relative band intensity of the $1605 \mathrm{~cm}^{-1}$ band to $1623 \mathrm{~cm}^{-1}$ band shows significant changes. Some of the relative band intensity increase at $1623 \mathrm{~cm}^{-1}$ may be due to the oxamate release from the complex upon temperature increase, which has a ${ }^{13} \mathrm{C}_{2}=\mathrm{O}$ stretch frequencies near $1620 \mathrm{~cm}^{-1}$, as shown in the Figures. 


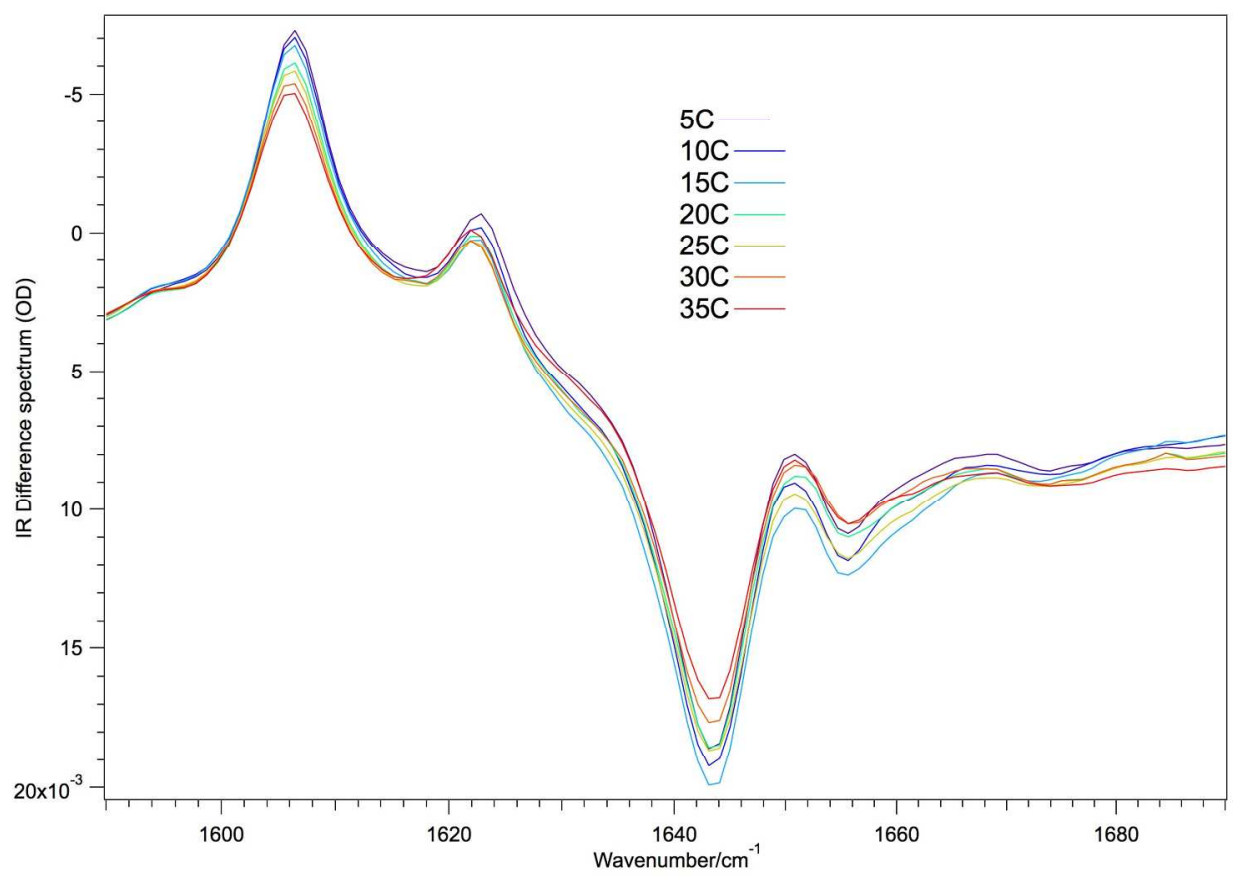

Figure 2Sa. Temperature dependence of isotope edited IR difference spectra of phLDH•NADH•oxamate.

For cgLDH, there is a negative band near $1627 \mathrm{~cm}^{-1}$ at room temperature, which may be tentatively assigned to the $\mathrm{C}_{2}=\mathrm{O}$ stretch of the unlabeled oxamate complex. Upon ${ }^{13} \mathrm{C}_{2}$ labeling of the oxamate, this band frequency shifts $32 \mathrm{~cm}^{-1}$ to $1595 \mathrm{~cm}^{-1}$, similar to the $38 \mathrm{~cm}^{-1}{ }^{13} \mathrm{C}$ shift of the major oxamate $\mathrm{C}_{2}=\mathrm{O}$ band from $1644 \mathrm{~cm}^{-1}$ to $1605 \mathrm{~cm}^{-1}$. The lower frequency of this band indicate even stronger hydrogen bonding to the $\mathrm{C}_{2}=\mathrm{O}$ bond within this sub population of the complex. Upon temperature increase, the $1595 \mathrm{~cm}^{-1}$ band intensity changes little but the negative $1627 \mathrm{~cm}^{-1}$ band intensity decreases significantly and with a concomitant frequency decrease. This observation can be explained by the release of the oxamate from the complex with increased temperature. The free oxamate ${ }^{13} \mathrm{C}_{2}=\mathrm{O}$ stretch band, which is near $1620 \mathrm{~cm}^{-1}$, would reduce the negative band intensity near $1627 \mathrm{~cm}^{-1}$ and shift its band position towards lower frequency. 


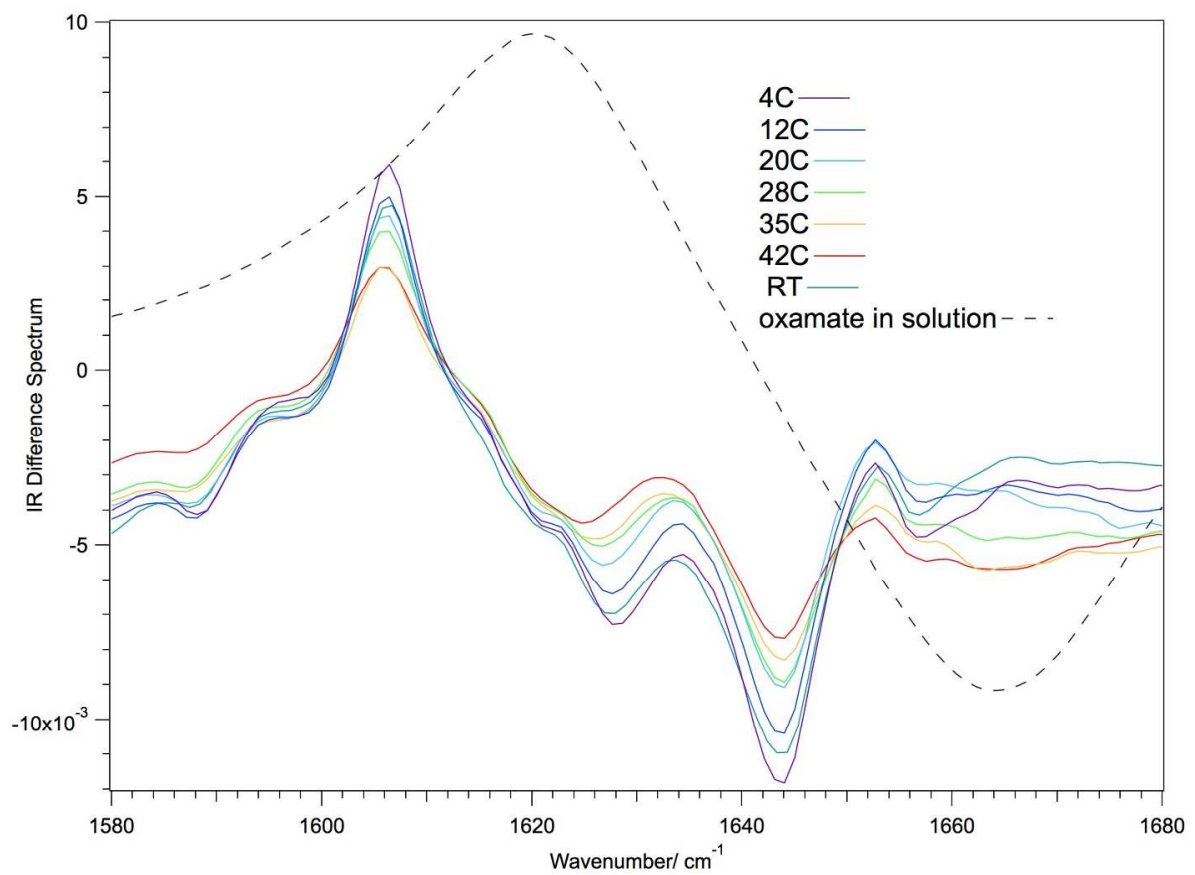

Figure 2Sb. Temperature dependence of isotope edited IR difference spectra of $\operatorname{cgLDH} \bullet \mathrm{NADH} \bullet$ oxamate

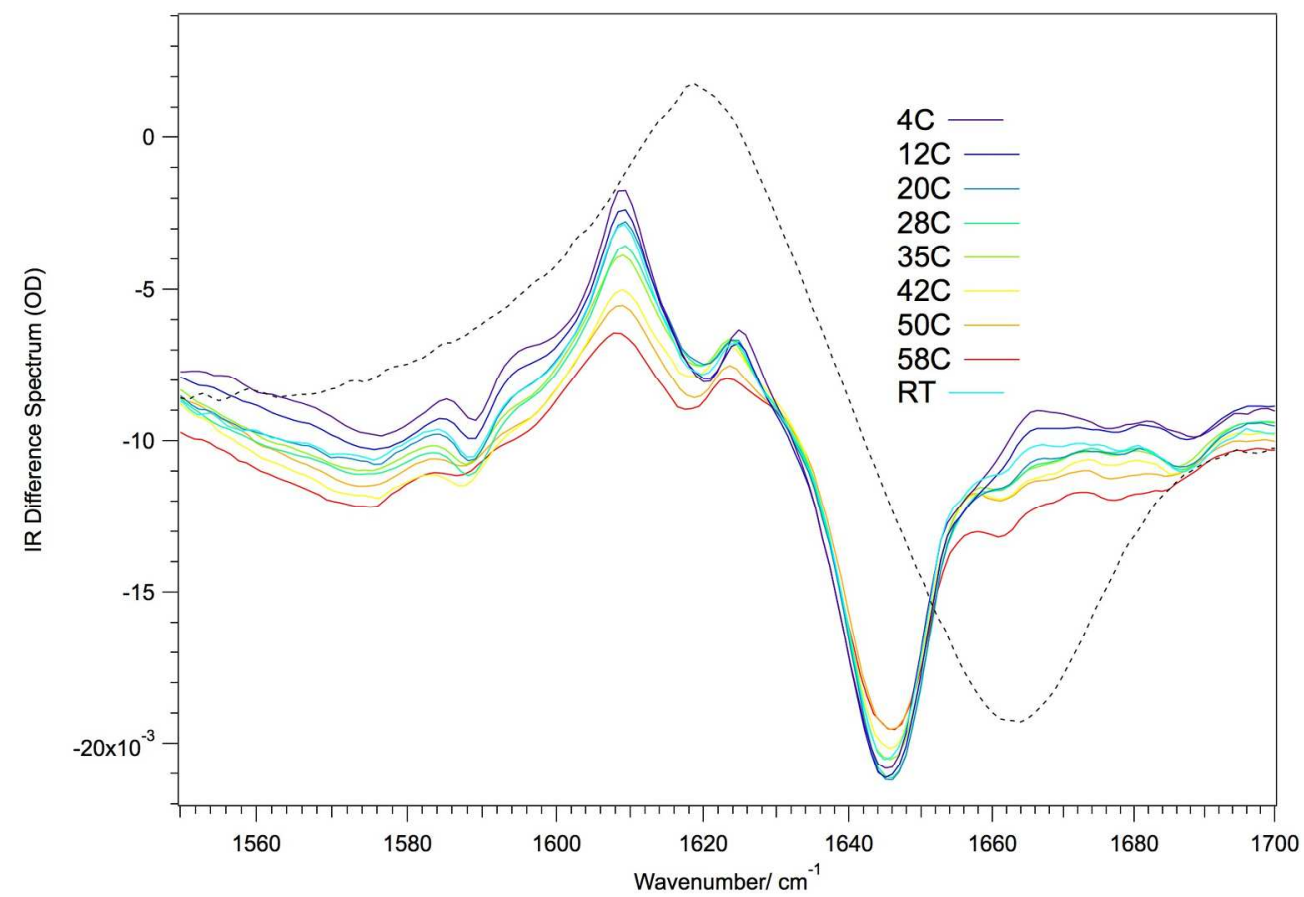

Figure 2Sc. Temperature dependence of isotope edited IR difference spectra of tmLDH•NADH•oxamate. 


\section{OBERVED RELAXATION TIMES AS A FUNCTION OF FREE OXAMATE AND BINARY COMPLEX}

Fast kinetic studies, such as the laser induced temperature jump relaxation spectroscopy used here, often reveal a number of kinetic processes. In relaxation studies, it is possible to disentangle bi-molecular reactions, such as the binding of oxamate to $\mathrm{LDH} \cdot \mathrm{NADH}$, from unimolecular reactions, such as a change from one conformer of $\mathrm{LDH} \cdot \mathrm{NADH} \bullet$ oxamate to another. This technical problem has been studied in substantial detail in work from the 1960s. ${ }^{8-10}$ In our work on the oxamate mimic, we have performed detailed studies of the phLDH system. ${ }^{11-}$

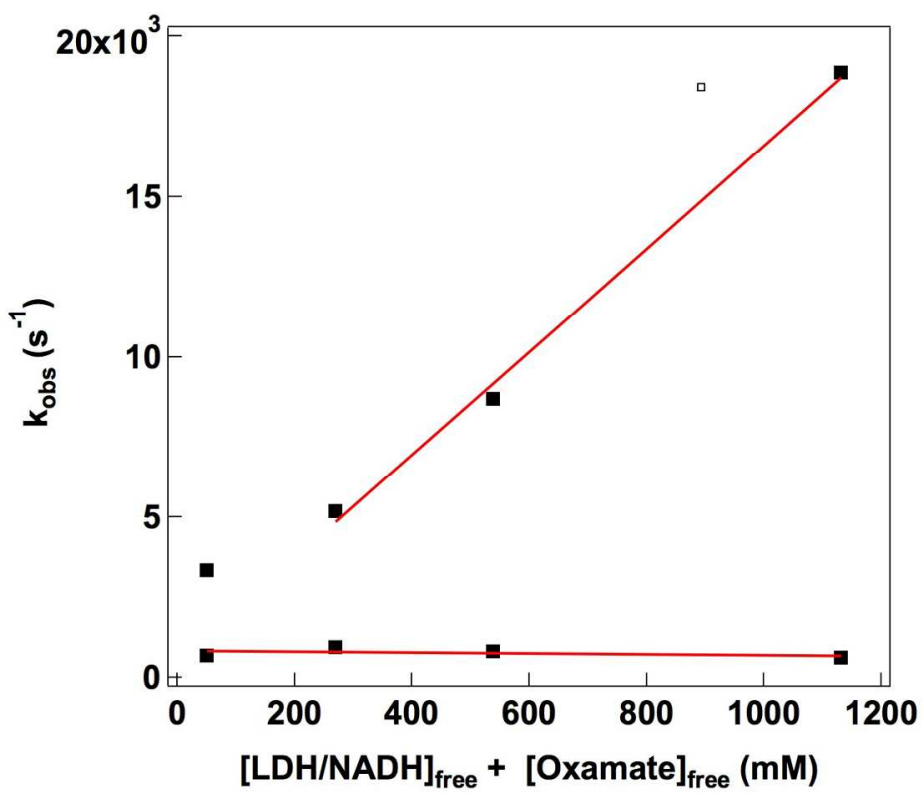

Figure 3S. Observed relaxation times from T-jump studies of the NADH emission of $\mathrm{tmLDH} \cdot \mathrm{NADH} \bullet$ oxamate as a function of free tmLDH•NADH plus oxamate. Initial concentrations for tmLDH•NADH•oxamate are: 50/50/50, 50/50/300, 80/80/600, 80/80/1200 $\mu \mathrm{m}$. $100 \mathrm{mM}$ phosphate with $3 \mathrm{mM}$ FBP buffer. $\mathrm{pH}=7,22-24^{\circ} \mathrm{C}$.

Figure 3S shows the observed relaxation times from T-jump studies of NADH emission on tmLDH $\bullet \mathrm{NADH} \bullet$ oxamate as a function of the concentration of free binary complex, 
tmLDH•NADH, plus free oxamate. The slope of the branch showing linear behavior under pseudo-first order conditions of free oxamate yields $k_{\text {on }}$ for the binding of oxamate to tmLDH•NADH. ${ }^{13}$ The lower branch that is largely independent of oxamate concentration is a uni-molecular event with a relaxation time of $606 \mathrm{~s}^{-1}$.

On the other hand, if the bi-molecular binding reaction holds a very fast equilibrium as compared to the following uni-molecular processes, the observed relaxation constant becomes a function including the microscopic rate constants in both processes as follows;

$$
k_{\mathrm{obs}}=k_{2} \frac{k_{1}([\mathrm{E}]+[\mathrm{S}])_{\text {free }}}{k_{1}([\mathrm{E}]+[\mathrm{S}])_{\text {free }}+k_{-1}}+k_{-2}
$$

where, $k_{1}$ and $k_{-1}$ stand for the forward and backward rate constants, respectively, of the bimolecular binding reaction, while $k_{2}$ and $k_{-2}$ are of the uni-molecular process that follows the binding reaction. The T-jump relaxation kinetics of the NADH emission from $\operatorname{cgLDH} \bullet \mathrm{NADH} \bullet$ oxamate complex showed such a coupling of bi- and uni-molecular rate constants (Fig. 4S, closed circles), where the observed relaxation constant in a few different temperature conditions was plotted against the concentration of oxamate in the sample. Because the oxamate concentration $(300-4800 \mu \mathrm{M})$ tested was much higher than that of LDH $(80 \mu \mathrm{M})$, the data of observed relaxation constant were analyzed using a simplified form of Eq. S1;

$$
k_{\mathrm{obs}}=k_{2} \frac{k_{1}[\text { oxamate }]}{k_{1}[\text { oxamate }]+k_{-1}}+k_{-2}
$$

which is a function of experimental oxamate concentration, instead of the sum of free LDH and oxamate concentrations. 


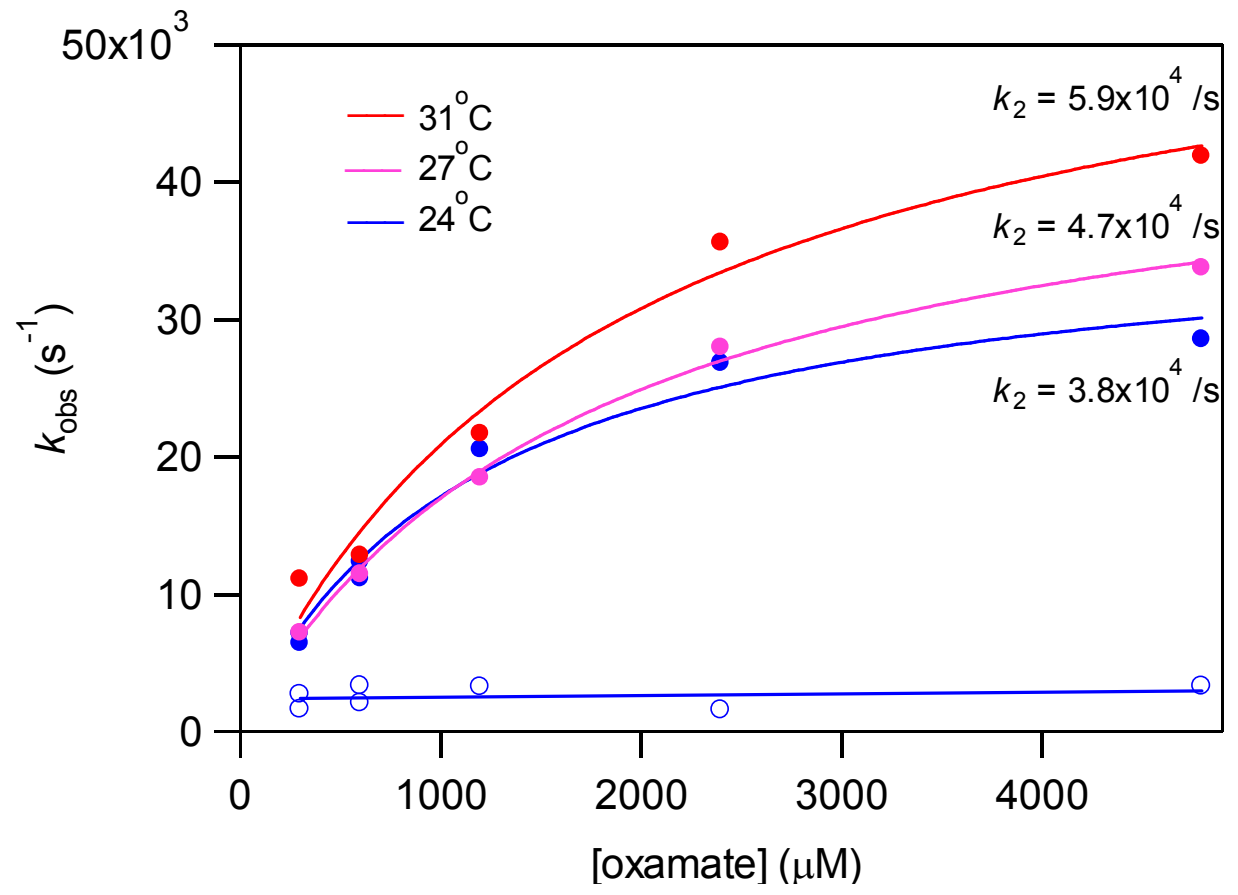

Figure 4S. Observed relaxation times from T-jump studies of the NADH emission of $\operatorname{cgLDH} \bullet \mathrm{NADH} \bullet$ oxamate as a function of free $\mathrm{LDH} \cdot \mathrm{NADH}$ plus oxamate. The data of fast relaxation process were denoted by closed circles, while those of the slow process at $24^{\circ} \mathrm{C}$ were shown by open circles.

The microscopic rate constant $k_{2}$ was calculated using Eq. S2 for the temperature conditions as shown in Fig. 4S, though $k_{-2}$ values were too small to determine accurately. The $\Delta \mathrm{H}$ and $\Delta \mathrm{S}$ values in Table 1 were derived from the $k_{2}$ values at temperature conditions shown here. On the other hand, the slow relaxation constant showed no clear dependence on the oxamate concentration, as exemplified by the data at $24^{\circ} \mathrm{C}$ (open circle in Fig. $4 \mathrm{~S}$ ), as well as no clear temperature dependence (not shown). The slow and fast relaxation constant values in Table 1 are those taken from the data at $24^{\circ} \mathrm{C}$ and $4800 \mu \mathrm{M}$ oxamate. 


\section{REFERENCES}

1. Deng, H.; Brewer, S. H.; Vu, D. V.; Clinch, K.; Callender, R.; Dyer, R. B., On the Pathway of Forming Enzymatically Productive Ligand-Protein Complexes in Lactate Dehydrogenase. Biophys. J. 2008, 95, 804-813.

2. Deng, H.; Vu, D. V.; Clinch, K.; Desamero, R.; Dyer, R. B.; Callender, R., Conformational heterogeneity within the Michaelis complex of lactate dehydrogenase. J. Phys. Chem. B 2011, 115, 7670-6778.

3. Peng, H.-L.; Deng, H.; Dyer, R. B.; Callender, R., The Energy Landscape of the Michaelis Complex of Lactate Dehydrogenase: Relationship to Catalytic Mechanism. Biochemistry 2014, 53, 1849-1857.

4. Deng, H.; Zheng, J.; Clarke, A.; Holbrook, J. J.; Callender, R.; Burgner, J. W., Source of Catalysis in the Lactate Dehydrogenase System: Ground State Interactions in the Enzyme•Substrate Complex. Biochemistry 1994, 33, 2297-2305.

5. Reddish, M.; Peng, H.-L.; Deng, H.; Panwar, K. S.; Callender, R.; Dyer, R. B., Direct Evidence of Catalytic Heterogeneity in Lactate Dehydrogenase by Temperature Jump Infrared Spectroscopy. J. Phys. Chem B 2014, 118, 10854-10862.

6. Chen, Y.-Q.; van Beek, J.; Deng, H.; Burgner, J.; Callender, R., Vibrational Structure of NAD(P) Cofactors Bound to Several NAD(P)-linked Enzymes: an investigation of ground state activation. J. Phys. Chem. 2002, 106, 10733-10740.

7. van Beek, J.; Deng, H.; Callender, R.; Burgner, J., Vibrational Structure of NADH Cofactors Bound to Glycerol-3-Phosphate Dehydrogenase and Dogfish Lactate Dehydrogenase. J. Raman Spec. 2002, 33, 397-403.

8. Eigen, M.; De Maeyer, L. D., Relaxation Methods. In Technique of Organic Chemistry, Friess, S. L.; Lewis, E. S.; Weissberger, A., Eds. Interscience: New York, 1963; Vol. 8, pp 8951054.

9. Bernasconi, C. F., Relaxation Kinetics. Academic Press: New York, 1976; p 1-288.

10. Cantor, C. R.; Schimmel, P. R., Biophysical Chemistry. W. H. Freeman and Company: San Francisco, 1980; Vol. 3, p 849-1371.

11. Deng, H.; Zhadin, N.; Callender, R., The Dynamics of Protein Ligand Binding on Multiple Time Scales: NADH Binding to Lactate Dehydrogenase. Biochemistry 2001, 40, 3767-3773.

12. McClendon, S.; Vu, D.; Clinch, K.; Callender, R.; Dyer, R. B., Structural Transformations in the Dynamics of Michaelis Complex Formation in Lactate Dehydrogenase. Biophysical J. 2005, 89, L07-L09.

13. McClendon, S.; Zhadin, N.; Callender, R., The Approach to the Michaelis Complex in Lactate Dehydrogenase: the substrate binding pathway. Biophysical J. 2005, 89, 2024-2032. 